\title{
EMPIRICAL STUDY OF GOOD, BAD AND UGLY MODULAR ENGINEERING SOLUTIONS IN MACHINERY MANUFACTURING INDUSTRY
}

\author{
Juuti, Tero; Pakkanen, Jarkko; Lehtonen, Timo
}

Tampere University

\begin{abstract}
This study examines the relationship between the product structuring principles chosen in modular product families and the business results of companies. In the three case studies of the article, it can be seen that products that meet the modularity definitions discussed in the literature have been able to utilise the benefits of modularity in a very varied way. In one business case, the effect of modularity on business has been negative. In two other cases, the effect has been positive - in one of these even the profitability of the business has significantly improved. The aim of this article is to identify whether product designing consistently has been following some product structuring principles previously mentioned in modularisation literature or whether case studies bring new principles to consciousness. In all case studies, the product structuring principles used are also discussed in the previous modularisation studies at a varying extent. In the discussion section, we raise the question of whether the recording and use of product structuring principles in design briefs could lead to making the product design decisions that affect the business positively.
\end{abstract}

Keywords: Modularisation, Design methods, Product families, Product architecture, Product structuring

Contact:

Pakkanen, Jarkko Tapani

Tampere University of Technology

Mechanical Engineering and Industrial Systems

Finland

jarkko.pakkanen@tut.fi

Cite this article: Juuti, T., Pakkanen, J., Lehtonen, T. (2019) 'Empirical Study of Good, Bad and Ugly Modular Engineering Solutions in Machinery Manufacturing Industry', in Proceedings of the 22nd International Conference on Engineering Design (ICED19), Delft, The Netherlands, 5-8 August 2019. DOI:10.1017/dsi.2019.305 


\section{INTRODUCTION}

Specific design rules for individual products have been presented in the literature. Many practical examples have been presented, for example, in engineering design books written by Pahl and Beitz (2013) and Ehrlenspiel et al. (2007). These design rules illustrate, by way of example, good and bad design solutions, with emphasis on the embodiment design phase and the structures to be produced in different ways (e.g. casting, sintering, turning, milling, welding) and for example ease of assembly. For instance, avoid designing a welding seam in high-stress regions. Solutions, assemblies or parts, optimised according to a particular perspective, are also often discussed under the design for X concept, where $\mathrm{X}$ is a specific focus that is specifically addressed (for example life cycle phase) (Huang, 1996). In this paper, however, our attention is no longer attached to, for example, good practices in individual weldable structures, but we are interested in finding out what kinds of design rules or principles have been identified to support realising modular product structures.

The difference between modular products and individual (integral) products is perhaps the easiest to describe from the point of view of product architecture, including alternatives for integral and modular architecture. According to Fellini et al. (2006), product architecture describes how the components are interrelated or arranged within the product. Fujimoto (2007) continues to explain that in an integral architecture, parts interact with complex and overlapping ways and it is difficult to change elements without modifications, while in modular architecture, effects occur through clearly defined interfaces. Andreasen (2011) describes modular architecture more precisely by pointing out that modular architecture is designed to meet a particular need for variety and increases commonality for efficient use of resources, reduces effects of complexity in operations, and aims providing benefits in areas that can be expected to have positive effects. He also adds that modular architecture supports product configuration and suggests that modules, interactions and interfaces should be defined when designing modular architecture. In summary, it can be stressed that in modular products it is not enough that the product is functional and cost-effective, but that it must also be efficiently variable.

Modularity has been addressed with a wide range of products and systems such as handheld power tools (Meyer and Lehnerd, 1997), mobile work machines (Pakkanen et al., 2019), and also production systems (Järvenpää et al., 2018; Siltala et al., 2016). Based on these few examples, it can already be said that the principles of modularity have been applied in many different environments, but, for example, by looking at the individual modularisation methods, it is difficult to give an unambiguous answer to what steps modularisation involves. This can be seen, for example, by studying the review articles written on the subject (Borjesson, 2010; Krause and Ripperda, 2013; Okudan Kremer and Gupta, 2013). The concepts of modularity have already been discussed for quite some time. Commonality and combinability studies have been published since the 1960s (Salvador, 2007). Considering this, perhaps, it is somewhat surprising that similar collections of design rules or principles have not yet been created in the modularisation research area to guide, for example, the conceptualisation and the embodiment design phase, as in the engineering design of the individual products we talked about at the beginning of the introduction.

We try to respond to this research goal by reviewing literature in the field and utilising material gathered from industrial modularisation projects we have participated in and we are familiar with. The second section discusses literature with the aim of finding concrete recommendations on principles supporting the engineering design of modular products. Subsequently, the third section reviews industrial modularisation projects and the role of these projects in business operations. The goal is to identify different principles used in realising modular product structures. Finally, it will be discussed whether the identification of company-specific principles and their use as a guideline for modularisation would be conducive to business-friendly decisions at engineering design in Sections 4 and 5.

\section{PRACTICAL PRINCIPLES FOR MODULARISATION IN LITERATURE}

There are various practical examples of how the modularisation can be applied to manage variety. In this section, these examples are briefly described based mainly on literature.

Modularisation based on the division of product into functions and considering each function as its own modules is probably one of the most well-known approaches to modularisation. This is discussed in engineering design books such as by Pahl and Beitz (2013) and Ulrich and Eppinger (2008). Erixon's (1998) Modular Function Deployment is one of the methods based on function-based product structure 
thinking. In addition to presenting generic module drivers as key elements for modularisation, Erixon also discusses how modular concepts can be evaluated. Two different types of concepts, base part assembly and "hamburger" assembly, are presented in this context. The parts that might change in the base part assembly are only fixed in the base unit, while in hamburger the parts are stacked on top of each other. Base part assembly is good engineering principle at illustrating how to reduce unexpected consequences of variation and to facilitate interface management. For example, if a product has a large steel structure that can be standardized and thus thought of as a base unit, then the variable assemblies are attached only to this and not to each other.

Principles of realising modular product structures have been discussed in several publications focusing on the truck and passenger car industry. The truck manufacturer Scania has presented that, for example, their fourth-generation trucks have been modularised (Lehtonen et al., 2009). The truck product brochures show that customers can choose any combination of listed major components with variants such as engines, power lines and cabins. If customers have heard about a modular product solution, they often expect this kind of freedom of choice. From the perspective of effective customisation, the fact that the main components must have similar interfaces is the basis for the full interchangeability of the main components. Another topic of discussion in the truck industry has been that how to simplify design coordination, to facilitate variety management in production and assembly, and to increase certainty for collision-free packaging. The goal is typically to save money while still preserving product variability. As a solution to this challenge, MAN, a truck manufacturer, introduces a reduction in the use of different product layouts by standardisation, with the installation space reserved for varying components (Förg et al., 2014). The starting point is the mapping of layout options and their features, taking into account, for example, sales volumes and priorities of variants. In the above-mentioned publication, it was concluded that the inflexible layout formalisation is the most effective as it provides the best predictability from the packaging space. Holmqvist (2004) continues in the truck context, showing an example where the vehicle manufacturer has divided the chassis of their trucks into four sections. Each individual section realises a particular set of variety. The idea of the sections is that the variability associated with each section should not affect other sections. Thus, this example is very close to MAN's reflection so far, but as a difference, Holmqvist also discusses the meeting points (bases) of the sections. According to him, a good location for the base is a place where the set of interfaces, parts, and different entities of the product is stable and able to form the base for the defined variation. Different principles for managing variation have also been presented in the passenger car industry. Volkswagen has introduced Modular Querbaukasten (MQB) toolkit approach, which utilises standardisation and modularisation for products and production systems (Winterkorn and Pötsch, 2012). The company has standardised things that customers do not expect variety. Thus, this approach takes into account the management of company's internal variety. Volkswagen has standardised certain portions and dimensions of different car models, developed standard physical attachment points for parts, and thus the physical assembly platform has been made adaptive to different part selections.

In addition to the automotive industry, concrete implementations of modularity, such as the implementation of interfaces, can also be seen in other industrial sectors. Standardised positions and connections for accessories, wiring, and pipes support product upgrades and allow, for example, production to start without the need to know what accessories should be available. Standardised locations and interfaces also support the standardisation of assembly and erection work. Examples of using a standard interfaces for accessories are accessory mounting rails for small arms weapon systems (United States Department of Defense, 1995) and Universal Serial Bus (USB) connectors on computers (USB Implementers Forum, n.d.).

In this section, practical principles for modularisation found mainly in the literature were briefly presented. Table 1 below summarises the findings. As can be seen from these examples, many of the principles were found in the vehicle industry. In the next section, we will look at industrial modularisation projects where we have been directly or indirectly involved and discuss what principles have been used in those.

Table 1. Summary of the identified principles for realising modular structures

\begin{tabular}{|l|c|r|}
\hline Reference(s) & Identified principles & Product type(s) \\
\hline (Pahl and Beitz, 2013; & \#1. Develop modules so that a module can perform a & $\begin{array}{r}\text { E.g. bicycle } \\
\text { components }\end{array}$ \\
\hline
\end{tabular}




\begin{tabular}{|l|c|r|}
\hline (Erixon, 1998) & $\begin{array}{c}\text { \#2. Design a base unit into the product, to which all } \\
\text { the varying modules are attached primarily and not to } \\
\text { other module variants }\end{array}$ & not defined \\
\hline (Lindh, 1992) & $\begin{array}{c}\text { \#3. Design the main modules as fully interchangeable } \\
\text { (the main module variants must have the same } \\
\text { interfaces) }\end{array}$ & Truck \\
\hline (Förg et al., 2014) & $\begin{array}{c}\text { \#4. Allocate the space in the product for different } \\
\text { modules and make space reservations for them } \\
\text { (Holmqvist, 2004) }\end{array}$ & $\begin{array}{c}\text { \#5. Define "change stop zones" between variant } \\
\text { elements to make modular product architecture } \\
\text { resistant to engineering changes and to ensure that } \\
\text { alternative modules fit physically into place }\end{array}$ \\
\hline $\begin{array}{l}\text { (Winterkorn and Pötsch, } \\
\text { 2012) }\end{array}$ & $\begin{array}{r}\text { \#6. Take advantage of standardisation where the } \\
\text { customer does not need product variation }\end{array}$ & Truck \\
\hline $\begin{array}{l}\text { (United States Department } \\
\text { of Defense, 1995; USB } \\
\text { Implementers Forum, n.d.) }\end{array}$ & $\begin{array}{c}\text { \#7. Design standardised positions and connections for } \\
\text { accessories, wiring, cabling, pipes and hoses }\end{array}$ & $\begin{array}{r}\text { Weapon } \\
\text { systems, USB } \\
\text { connectors }\end{array}$ \\
\hline
\end{tabular}

\section{THREE MODULARISATION PROJECTS}

This section includes three product modularisation projects. First, we study tunnel drill rigs, after which we discuss locomotives. Finally, a side rolling hatch cover project is presented.

\subsection{Tunnel drill rig}

Tunnel drill rigs are mobile construction machines, which are used, for example, in mines and in the construction of railway and road tunnels. This development work was carried out in 2012-2013 in a Swedish-owned company that is one of the leading companies in delivering these kind of mobile machinery intended to drill hard rock types like granite. The authors participated in the development project.

\subsubsection{Development work and business results}

This modularisation project is based on a product renewal project, where new generation of products was developed. The ambitious goal of the project was to increase the share of large module assemblies in three previously distinct products, of which the tunnel drill rig was one. The aim was to have one configurable rear carrier that could be used in three different-purpose machines. The rear carrier of the drill rig includes machine drive motor, hydraulic power generator for the drill, cooling system, and connections to the electricity and water network of a mine or a tunnel site using cable and hose reels. The other two specially designed machines for different applications contained a similar structure, but the main parts were of different design and features.

The design task was challenging because the dimensions of the machines are limited by the size of the tunnel. The rear carrier shall not be higher than the rear window of the cabin, as the cockpit of the machinery in a cramped environment must have a free view in all directions in the tunnel. The length of the machine cannot be increased freely because, in the mines especially, the machine must be able to turn in a small space. In addition, the centre of gravity of the main components must be taken into account as the machine is also driven on inclined surfaces. These factors lead to a compact packaging of items in the rear carrier.

The different devices of the previous generation could not be used as the starting point for design. This is because the rear carrier architecture was completely different. The large packaging density of the machines had been optimised in different machines in different ways. For the new generation, a completely new layout was designed, which made it possible for all three machines to be made from the same product architecture.

The value of the development work was measured in reduced design hours. When the hours used to design a common architecture were reduced from the design hours of the first completed product that was a tunnel drill, the designing could be done within the same time and amount of work that the project plan would allocate for the development of a non-modular machine. Two of the following developed machines benefited from the common modular rear carrier so that only specific modules for these 
applications had to be designed. For rear carriers, the time savings totalled approximately one full rear carrier design time.

During the development project, developers came up with a new surprising challenge regarding the product family. It was decided to include a machine with a different technology, whose patent and design rights had been available for use by the company. This technology was not taken into account when designing the rear carrier architecture and it was not possible to use it without breaking the architecture in many places. The situation was largely the same as that of the locomotive engines in the following project explained in Section 3.2, but the result was different. The principles used in modularisation outlined in the next section led to the existing architecture being utilised to guide the changing needs. In the final work hour calculations, it was found that although the total number of days included architectural work, the development project saved tens of percent of working hours for the rear carrier as compared to a separate machine development project.

In the latter years, the company benefitted from the maintenance of the product and in the reduced variety of spare parts. Three of the models of the collection used the same modular rear carrier and one model in some respects a similar rear carrier. However, the company will retain more detailed information about these savings achieved as business secrets.

\subsubsection{Principles of realising modular product structure}

From the outset it was clear that the most challenging task was to find a layout for the main components allowing the rear carrier to be reused in different applications. The interchangeability of the modules would require good control of the interfaces of the application-specific modules.

Initially, the correct module division was searched by a modularisation method called Brownfield Process (Pakkanen et al., 2016). The positioning of the modules with the heaviest components was started according to the space reservation model (principle \#4 in Table 1). The module variants were presented using 3D envelope models that depicted the greatest dimensions of the variants. These were used to find a suitable architecture. Modules that were considered problematic were modified by moving components to other modules or changing their technical implementation. The 3D envelope models were very light, so they made it possible to experiment with quick architectural variations. Finally, these models were to be used in the documentation of modular architecture.

In many cases, the modules required for different applications differed very much from each other. Managing this challenge was a problem in a tightly packaged machine. Therefore, two design strategies for the product design were chosen at the beginning of the design. An unalterable standard part was designed to carry a mechanical load on the carrier and this part would act as a mechanical anchorage point (base unit) for all modules (principle \#2 in Table 1).

In addition, it was decided that, in addition to the mechanical attachment, all electrical, hydraulic, compressed air and fluid connections are routed through the base part along specially designed routes (principle \#7 in Table 1). This resulted in a product structure in which the changing modules were only connected to the standard part rather than to the other modules that changed due to customer requirements. The change stop zones of the change were defined between the modules that were estimated to be difficult to predict for future modification needs and new product versions (principle \#5 in Table 1). Finally, the interfaces were described and attached to 3D space reservation models.

The resulting modularity was beneficial for the business as it increased the efficiency of product development and product maintenance work as expected. The design made through the space reservation and envelope models clarified the structure of the machine so that it became a more mature and legitimate looking result from the engineering point of view. For example, the number of parts with many unrelated functions decreased. In machine design, similar thinking about independent functions (principle \#1 in Table 1) is presented by, for example, Pahl and Beitz (2013) when they speak of the principle of the division of tasks. The result was from the technical design point of view so good that the design team got into a discussion about whether a well-made design work in any case would have led to these solutions even if the modularity was not emphasised in design. Of course this is impossible to find out afterwards. However, according to the research team, it would have been very unlikely that the old model of the machine would have been completely modified unless the ambition of the modular structure enabling design reuse had forced it. The results presented in Section 4 discusses more about why the modular structure was successful. 


\subsection{Diesel locomotive}

This development work of modular diesel locomotive was made at Valmet (later Transtech) rolling stock factory in Finland in 1982-92. The authors of this paper were not active designers in this project, but the observations and data collection here are based on interviews, research made by the authors and a book written about this development project and locomotive-type (Lehtonen, 2007; Pentikäinen, 2006). Today the Transtech company is owned by Škoda and has been successful in building railway carriages and trams during the last years.

\subsubsection{Development work and business results}

Invitations for tender for the new, general-purpose diesel locomotive for Finnish National Railways were sent in 1982. The actual agreement for purchase was made on November, 1983 with Valmet covering the delivery of two prototype locomotives to be delivered in 1985-86 and 21 locomotives to be delivered in 1987-1991 (Pentikäinen, 2006). These 23 locomotives of the first batch were supposed replace old locomotives. In addition, there seemed to be prospect of replacing about 150 locomotives of newer types in Finland only, and the locomotive was designed for export as well. In 1989, as the locomotive approached the readiness of serial production, it was estimated that several hundreds of diesel locomotives of this size range that were over 20 years old were used in the Nordic countries.

Valmet's model name for the product was an M locomotive. The letter M was reported to stand for "a modular structure", "modern technology", "modifiable" and "multiple uses". The type name of the fouraxle all-purpose M locomotive was Dr16 (a diesel engine, heavy axle weight, type 16). It was capable of high speeds of express trains, but it had tractive effort and capability of maintaining high power output at low speed, which was required in heavy goods trains. Valmet co-operated with Oy Strömberg Ab that developed the electrical transmission for the locomotive that enabled more precise steering and improved utilisation of friction at start up. This kind of locomotive is able to pull a heavier train than one equipped with a direct-current motors. In addition, the alternating-current motors require less maintenance and they are often smaller and lighter. The $\mathrm{M}$ locomotive was one of the first diesel locomotives in the world to be implemented with this technology. The equipment in the frequency converter implemented with thyristors had been collected in the electrical equipment module.

The customer wanted to try the engines of two manufacturers, Wärtsilä and Pielstick, in the prototype locomotives but it was discovered that the Wärtsilä engine could not be made lightweight enough to reach the total weight limit. Wärtsilä said that they would develop a new eight-cylinder V8 engine for the locomotive, but it would take some time to manufacture these. The prototype series increased to four locomotives, of which two would have a Pielstick engine and two a Wärtsilä engine. The engine change considerably affected the structure. For example, total length was reduced from 19 metres to 17.6 metres. In October 1986, the new Wärtsilä engine was finished, and the manufacturing locomotives could continue. Even though the engine alternatives had similar outer dimensions, they still required changes in the machinery located in front of the engine as well as in the structures at the back.

All four prototype locomotives entered test and typification runs in 1987. The test runs and tests on the locomotives were carried out over the two years that followed. The first serial-production locomotives were finished in 1990. At this stage, the development project was badly delayed. In addition, a dispute arose between the supplier and the customer on the poor operational reliability of the prototype locomotives. Around New Year's in 1990-91, the prototype locomotives were removed from traffic for a while. There were no problem in the serial production of the locomotives, and they were manufactured according to schedule. The last locomotive was delivered in June 1992.

However, the locomotive project failed as a product development project. The practical operational reliability of the locomotive was poor. For example, in August 1992, nine locomotives were removed from traffic due to malfunctions (39\% of the total number of locomotives). During January-October, locomotives failed on the line 23 times for each million kilometres run. The corresponding figure for the old Dr13 locomotives of the early 1960s was 17. The National Railways did not place a new order for locomotives. The M locomotive was offered for many other operators as well. New locomotive deliveries did not take place. The failed modularisation project resulted in the closure of the factory in Tampere and the exit of the locomotive business, which began in 1901.

\subsubsection{Principles of realising modular product structure}

Modularisation ideas in the Valmet were based on the project manager's experiences of working at Lokomo Oy. Problems were encountered in Lokomo's previous locomotive projects when pneumatic 
appliances were located in different areas of locomotive. In the C600 locomotive, these appliances were collected in a frame specifically designed for this purpose. The pneumatic valves and tanks were attached to the frame that was lifted to the locomotive as a whole and then joined to the pipeline. Project manager thought this solution based on assembly-based modularity (a new principle not presented in Table 1) could be used on a wider scale as well (Pentikäinen, 2006).

The new Valmet M locomotive was designed and manufactured as modular. The locomotive consisted of approximately 30 constructional elements of which some were called modules, some elements, and some only components. We can also see clear function-based modular divisions in its design (principle \#1 in Table 1). The modularity implemented brought about benefits in the construction of the locomotive. Modularity was utilised already in the management of the product development project. A wall chart method was used in which the design phases of the modules were visible to all participants (Pentikäinen, 2006). The cable and pipe system module assembled in connection with the frame enabled assembly in a comfortable working position. The device entities could be tested before assembly (a new principle not presented in Table 1). The simple-to-assemble machine covers also speeded up assembly and later facilitated service operations. In the design, opportunities for the common use of the components were considered with the electric locomotive variant that was foreseen at the time. It was hoped that the cabin module could be used as such in future locomotive models (Pentikäinen, 2006). The modular structure was supposed to support maintenance in general. The modular structure was strongly used in marketing - it was the first feature to be listed as the advantages of the locomotive.

In some areas, the assembly-based modularity did not succeed. This was the case, for example, with the engines. Pielstick engines were chosen for the serial-produced locomotives, and the customer also wanted to change the two locomotives with Wärtsilä engines. In practice, the changing of the engine would have led to replacing or changing all the equipment at the front of the locomotive, and the work would have cost approximately FIM four million. At the time, a new serial-produced locomotive cost FIM 13 million, of which the engine approximately one million (Pentikäinen, 2006). Modularity implemented for operational reliability did not improve the situation. It was reported that the modular structure did work in part as intended in service and repair, but in some areas the goals were not met. In 2006, operational reliability was still only barely satisfactory. The modular structures may even have reduced the operational reliability, which is indicated by the large alteration work performed on two locomotives in 2005. Part of the alteration work sought to raise the operational reliability of the electrical equipment "by removing unnecessary connectors" (Pentikäinen, 2006).

From product structuring and engineering viewpoint modular structure of the M-locomotive was well justified. The modular structure did not unnecessarily duplicate load bearing structures and the principle of direct and short force transmission path (Pahl and Beitz, 2013) was mainly followed from engineering perspective. Why the modular structure was failure is discussed later in Section 4.

\subsection{Side rolling hatch cover}

MacGregor produces hatch covers for bulk cargo carriers. The authors participated in the side rolling hatch cover (SRHC) development project as external consultants in 2011. MacGregor has discussed this development work and the business results in their publication (MacGregor, 2012). SRHCs are used in cargo ships that are transporting bulk materials like grain, iron ore or coal. There are two hatch covers on each opening in the ship. Like its name suggest, SRHC slides sideways on rollers, when opened.

\subsubsection{Development work and business results}

SRHCs are engineer-to-order (ETO) products. The waterproofness of the hatch is a critical factor in maintaining the cargo ship's buoyancy and stability. Consequently, those who classify ships give a lot of requirements for the design of the hatches. Wave load is the largest force on the hatch. According to the prevailing classification practice, the greatest durability is required at the ship's bow and the requirement always decreases to the fourth hatch pair with a cargo division that is used in modern ship sizes. A large bulk carrier therefore includes hatches considering four different stress scenarios. The size of the loading openings in the ship is optimised according to the ship's hull shape. At different points, the hatches on the ship are therefore of different sizes. Often one hatch is used as a helicopter landing pad. This hatch will follow its own additional requirements.

Even though SRHCs are an important part of the ship, they are small compared to the total costs of a ship and therefore the hatches are always engineered to the dimensions of the ship, and standardisation is difficult. The hatches are reasonably high on deck and therefore their weight needs to be optimised. 
The optimisation of the weight is also driven by the contract agreements used in the shipbuilding industry, where the estimated cost is directly tied to the weight.

For these reasons, the hatches are delivered as ETO products designed specifically for the series of ships. The change was desirable in this matter and MacGregor wanted to explore the possibilities of switching to the configure-to-order approach that is based on standardised, optional and customer-specific items (not only customer-specific items as in ETO). At first this seemed technically superior to achieve, as the structure of the hatch made the parametric models too complex to be maintained. The project undertook a review of different product structure alternatives and based on it the technical solution of the product was changed. Based on this, it was managed to design a configurable and modular family of SRHCs. This had a significant impact on business. According to the company's own information design time reduced from average 8 weeks to the fraction of that time (MacGregor, 2012). A few years after the development project, the number of ships with these hatches had exceeded the limit of one hundred vessels. Two prototype ships have both been six years in marine traffic without problems with SRHCs.

\subsubsection{Principles of realising modular product structure}

The challenge in the SRHCs was that the hatch-carrying and weight-optimisable steel structure was integrally connected to parts of the hatch cover locking, lifting and moving machinery. The locations of all parts depended on the size of the ship, the position of the hatch in the deck and the classification requirements related to the hatch. The original hatches could not have standard load bearing steel parts and the parametric engineering model that would be required would have been remarkably laborious and challenging to maintain.

The structure of the hatch was changed by leaving the force-carrying structures inside the hatch frame but by moving the opening and closing portions outside the frame. By dividing the hatch into design areas serving different functions, a fixed coupling between actuators and load-bearing structures could be taken apart. Independence was initiated by defining change stop zones between variable modules (principle \#5 in Table 1). The result was a structure that made it possible to make a parametric model and an IT-based configurator.

Although the product was a modular and business-friendly, considering pure machine design perspective, this structure would never have been selected. The principle of direct and short force transmission path (Pahl and Beitz, 2013) was not followed and in that sense the new design was inferior to traditional ones. This is acceptable as this concerns the forces associated with the hatch opening and closing. When opening or closing the hatch, the forces are much smaller than the forces caused by the wave load. From the point of view of the wave load, the new hatch easily fulfils the requirements. From the perspective of weight optimisation, the new hatch is similar to the old one.

Aesthetic values were also discussed during the development work. In the most stylish old SRHCs, all the technical details were hidden. In the new hatch, the technology is visible. Even though the edge of the hatch is steep, there is no extra weight in the hatch. Many thought that the new hatch was ugly compared to the old ones. However, this has not prevented business success.

\section{RESULTS AND DISCUSSION}

From the engineering viewpoint, the tunnel drill rig's new modular structure consisted of better design solutions than the previous version and the rig was more elegant. Modularisation also enabled business benefits such as reduced costs in product development and in product engineering (e.g. engineering documentation maintenance and minor updates on product design). The locomotive's modular design was good from the point of view of engineering even though a lot of electrical connectors were added to the product due to modularisation. Unfortunately, the reliability of the locomotive was significantly compromised because the connectors were unreliable and the train did not function properly. From a business point of view, one major challenge, for example, was to deliver locomotives with different engine types with cost-efficient way and competitive delivery time. Assembly-based modularity is wellknown industrial practice, but this principle did not support the business goals. The SRHC was based on the standardisation and parametric modular structure that supported configurability. Engineers did not favour the modular structure because it was not the best structure for weight optimisation. Nevertheless, the modular structure allowed many business benefits.

Based on these modularisation projects, we will ask the following question: why the modular structure was successful in two products but failed in one product? From the engineering point of view, all three 
were modular products. Even though the locomotive had a promising modular structure, the modularisation result was poor. The SRHC was the opposite of this. The modular structure was considered problematic, non-optimal and ugly but it was still a business success. We strongly suspect that the success could be due to the which principles of realising modular product structure were used, but we have to understand that there were other factors like technical risks affecting the business success. Table 2 provides a summary of the most obvious principles of realising modular product structures observed and utilised in the industrial projects. Compared to Table 1, the studied cases did not show strong links to the modularisation principles used by Volkswagen (principle \#6) nor to the interchangeability of the main module variants through standard interfaces discussed in truck industry (principle \#3). The similarity of the other principles presented in the literature with the principles used in industrial projects we studied was clearly more noticeable. The tunnel drill rig made use of several principles in modularisation. The embodiment design and the detail design were successful from the point of view of engineering and business. In the project of locomotive, the modularisation objectives came from a previous project in which modularisation was utilised to facilitate assembly work. The generic principles for realising modularisation were copied from the old project to the new project also emphasising function-oriented modularisation without the validation of the goals. In this case, it led to a modular structure, which did not support all of the business objectives. In the project of SRHC, the challenge was the initial situation in which company had to consider whether modularisation was a solution to business challenges at all. The value creation potential of the modular product was analysed by calculating the business impact with a new product concept with desired properties. The result of the estimating value creation potential was seen as promising and engineers were given the task of designing a modular SRHC based on different principles compared to the previous products. Finally, the principle of applying change stop zones dominated the new product concept.

Table 2. Summary of used principles ( $x$ : considered, empty: not considered)

\begin{tabular}{|l|c|c|c|}
\hline $\begin{array}{l}\text { Principles for realising modular product structure } \\
\text { identified in modularisation projects presented in Section 3 } \\
\text { (Principles \#3 and \#6 (Table 1) were not used in these } \\
\text { products and principles \#8 and \#9 are new) }\end{array}$ & $\begin{array}{c}\text { Tunnel } \\
\text { "Tilling rig } \\
\text { "The good" }\end{array}$ & $\begin{array}{c}\text { Locomotive } \\
\text { "The bad" }\end{array}$ & $\begin{array}{c}\text { Side rolling } \\
\text { hatch cover } \\
\text { "The ugly" }\end{array}$ \\
\hline $\begin{array}{l}\text { \#1. Develop modules so that a module can perform a } \\
\text { complete function }\end{array}$ & $\mathrm{x}$ & $\mathrm{x}$ & \\
\hline $\begin{array}{l}\text { \#2. Design a base unit into the product, to which all the } \\
\text { varying modules are attached primarily and not to other } \\
\text { module variants }\end{array}$ & $\mathrm{x}$ & & \\
\hline $\begin{array}{l}\text { \#4. Allocate the space in the product for different modules } \\
\text { and make space reservations for them }\end{array}$ & $\mathrm{x}$ & & $\mathrm{x}$ \\
\hline $\begin{array}{l}\text { \#5. Define "change stop zones" between variant elements } \\
\text { to make modular product architecture resistant to } \\
\text { engineering changes and to ensure that alternative modules } \\
\text { fit physically into place }\end{array}$ & $\mathrm{x}$ & & \\
\hline $\begin{array}{l}\text { \#7. Design standardised positions and connections for } \\
\text { accessories, wiring, cabling, pipes and hoses }\end{array}$ & $\mathrm{x}$ & & \\
\hline \#8. Define modules as separate assemblies in production & & $\mathrm{x}$ & \\
\hline \#9. Design modules for independent testing & & $\mathrm{x}$ & \\
\hline
\end{tabular}

\section{CONCLUSION}

Based on the studied literature and presented industrial projects, there are different principles for realising modular product structures. The study discusses if these principles have a connection to the product's success in a business environment. Although we found that the principles used in three industrial projects have relations to published studies, it seems that research could provide more support for modularisation, especially for the synthesis phase and embodiment design. For future research, the following questions arise. Is it possible to identify more principles to support realising modular product structures? How to link these principles with particular business objectives? We believe that focusing on these themes would increase understanding by making tacit knowledge explicit on the engineering techné and enable profitable business including delivering competitive products. 


\section{REFERENCES}

Andreasen, M.M. (2011), “45 Years with design methodology”, Journal of Engineering Design, Vol. 22 No. 5 , pp. 293-332.

Borjesson, F. (2010), “A systematic qualitative comparison of five approaches to modularity”, DESIGN 2010 11th International Design Conference, p. 147.

Ehrlenspiel, K., Kiewert, A. and Lindemann, U. (2007), Cost-Efficient Design, edited by Hundal, M.S., Springer, Berlin, Heidelberg, available at:https://dx.doi/org/10.1007/978-3-540-34648-7.

Erixon, G. (1998), Modular Function Deployment - A Method for Product Modularisation, The Royal Institute of Technology, Stockholm, Sweden.

Fellini, R., Kokkolaras, M. and Papalambros, P.Y. (2006), “Commonality Decisions in Product Family Design”, In: Simpson, T.W., Siddique, Z. and Jiao, J.R. (Eds.), Product Platform and Product Family Design, Springer, pp. 158-185.

Förg, A., Stocker, J., Kreimeyer, M. and Lienkamp, M. (2014), "Enabling modularisation potentials by standardized vehicle layouts", In: Laakso, M. and Ekman, K. (Eds.), Proceedings of NordDesign 2014, The Design Society, Espoo, Finland, pp. 754-764.

Fujimoto, T. (2007), Competing to Be Really, Really Good-The behind-the-Scenes Drama of Capability Building Competition in the Automobile Industry, International House of Japan, Tokyo.

Holmqvist, T. (2004), Managing Product Variety through Product Architecture, Chalmers University of Technology.

Huang, G.Q. (Ed.). (1996), Design for X - Concurrent Engineering Imperatives, Springer, Netherlands, Dordrecht, available at:https://dx.doi/org/10.1007/978-94-011-3985-4.

Järvenpää, E., Hylli, O., Siltala, N. and Lanz, M. (2018), "Utilizing SPIN rules to infer the parameters for combined capabilities of aggregated manufacturing resources", IFAC-PapersOnLine, Vol. 51 No. 11, pp. 84-89.

Krause, D. and Ripperda, S. (2013), “An assessment of methodological approaches to support the development of modular product families", Proceedings of International Conference on Engineering Design, ICED13, Aug 19-22, Sungkyunkwan University, Seol, Korea.

Lehtonen, T. (2007), Designing Modular Product Architecture in the New Product Development, Tampere University of Technology, Tampere.

Lehtonen, T., Juuti, T., Mela, J. and Riitahuhta, A. (2009), “On the development of product family architectures; Comparison of business-oriented and function-based product structuring", In: Norell Bergendahl, M., Grimheden, M., Leifer, L., Skogstad, P. and Lindemann, U. (Eds.), DS 58-2: Proceedings of ICED 09, the 17th International Conference on Engineering Design, Vol. 2, Design Theory and Research Methodology, Design Society, Palo Alto, CA, USA, pp. 167-178.

Lindh, B.-E. (1992), Scania and Its Vehicles, 1891-1991, Streiffert.

MacGregor. (2012), "Keeping research behind closed doors can be counter-productive", MacGregor News, No. 164 , pp. $18-19$.

Meyer, M.H. and Lehnerd, A.P. (1997), The Power of Product Platforms: Building Value and Cost Leadershop, The Free Press, New York.

Okudan Kremer, G.E. and Gupta, S. (2013), "Analysis of modularity implementation methods from an assembly and variety viewpoints", The International Journal of Advanced Manufacturing Technology, Vol. 66 No. 9-12, pp. 1959-1976.

Pahl, G. and Beitz, W. (2013), Engineering Design: A Systematic Approach, Vol. 11, Springer Science \& Business Media.

Pakkanen, J., Juuti, T. and Lehtonen, T. (2016), "Brownfield process: A method for modular product family development aiming for product configuration”, Design Studies, Elsevier Ltd, Vol. 45, pp. 210-241.

Pakkanen, J., Juuti, T. and Lehtonen, T. (2019), "Identifying and addressing challenges in the engineering design of modular systems - case studies in the manufacturing industry", Journal of Engineering Design, Vol. 30 No. 1, pp. 32-61.

Pentikäinen, P.P. (2006), Iso Vaalee (in Finnish), Petrin viestintä.

Salvador, F. (2007), "Toward a product system modularity construct: Literature review and reconceptualization", IEEE Transactions on Engineering Management, Vol. 54 No. 2, pp. 219-240.

Siltala, N., Järvenpää, E. and Lanz, M. (2016), "Formal Information Model for Representing Production Resources”, In: Nääs, I., Vendrametto, O., Mendes Reis, J., Gonçalves, R.F., Silva, M.T., von Cieminski, G. and Kiritsis, D. (Eds.), Advances in Production Management Systems. Initiatives for a Sustainable World, Springer International Publishing, Cham, pp. 53-60.

Ulrich, K.T. and Eppinger, S.D. (2008), Product Design and Development, McGraw-Hill, New York.

United States Department of Defense. (1995), "MIL-STD-1913".

USB Implementers Forum. (n.d.). "USB", available at: https://www.usb.org/.

Winterkorn, M. and Pötsch, H.D. (2012), "Volkswagen Golf VII: Launch of a new era”, Sardinia. 